\title{
BCOR/CCNB3 Fusion Gene
}

National Cancer Institute

\section{Source}

National Cancer Institute. BCOR/CCNB3 Fusion Gene. NCI Thesaurus. Code C139666.

A fusion gene that results from a paracentric chromosomal inversion inv $(X)$

(p11.4;p11.22) which fuses the stop codon of the BCOR gene to exon 5 of the CCNB3 gene. This fusion is associated with bone sarcomas. 